\title{
Cidade dos meninos em Duque de Caxias/RJ: crime ambiental anunciado
}

\section{1 | Introdução}

A presente pesquisa visa analisar e justificar os motivos da morosidade na resolução de crimes ambientais, mostrando o impacto ambiental decorrente da contaminação por organoclorados na população da Cidade dos Meninos em Duque de Caxias, município da Baixada Fluminense, no Rio de Janeiro. A inexistência de um planejamento para o desmonte da fábrica de inseticidas organoclorados acarretou sérios problemas de natureza ambiental com repercussões na saúde da população decorrentes do depósito de tais compostos organoclorados de forma inadequada sobre o solo, colocando em risco a saúde pública e o ambiente. Um cenário de impasses judiciais, onde todos questionam o problema, mas em que cada uma das partes segue interesses não convergentes, compromete diretamente todo o processo, inviabilizando a solução. O crescimento demográfico no município de Duque de Caxias possibilitou ainda a formação de assentamentos urbanos de baixa renda, acarretando não somente o agravamento dos problemas já existentes, como também a questão da contaminação da área por resíduos organoclorados, bem como o aumento da população exposta.

\section{2 | Área de estudo}

A Cidade dos Meninos fica localizada no município de Duque de Caxias, no km 12 da Avenida Presidente Kennedy, na região da Baixada Fluminense, sendo incorporada em março de 2002 ao Patrimônio da União e a partir desta mesma data está sob a guarda, em caráter de emergência, do Ministério da Saúde. O município de Duque de Caxias, onde se situa a Cidade dos Meninos, faz parte da região comumente chamada de Baixada Fluminense, que se caracteriza pela grande concentração de pobreza e de carência de infraestrutura urbana. Apresenta uma série de problemas ambientais classificados pelo órgão ambiental Estadual como críticos e caracterizados pela deficiência de sistemas de esgoto sanitário, degradação de áreas de preservação, deficiência de cobertura arbórea, precárias condições de vida, vetores, favelização e sub-habitação, refúgios de flora e fauna ameaçados, risco de acidentes, poluição de águas, inundações e enchentes, resíduos sólidos, polvição do ar, assoreamento de corpos de água, polvição de praias, aterros de corpos d'água, vazamento e lançamento de óleo. Duque de Caxias é o segundo pólo industrial da Região Metropolitana e do Estado do Rio de Janeiro, que abriga a Refinaria de Caxias (REDUC), maior unidade industrial da área do Grande Rio e uma fábrica de borracha sintética, indústrias que foram de grande importância para o desenvolvimento da região. Segundo

1 Universidade Castelo Branco: Escola Superior de Gestão e Tecnologia. Avenida Santa Cruz, 1631 - Realengo - Rio de Janeiro/ RJ, CEP: 21710-250. Telefone: (21) 3216-7700 - e-mail: impagliazzo@unidadezero.com 
dados do IBGE de 2010, estima-se uma população de aproximadamente 872.762 (oitocentos e setenta e dois mil setecentos e sessenta e dois) habitantes residindo em quase sua totalidade em área urbana. $\mathrm{A}$ área da Cidade dos Meninos possui aproximadamente 19.000.000 $\mathrm{m}^{2}$ (dezenove milhões de metros quadrados) e características predominantemente rurais. A Cidade dos Meninos tem aproximadamente 750 famílias, conforme cadastro realizado pelo município de Duque de Caxias em 2009.

\section{3 | A problemática}

Em 1950, o antigo Ministério da Educação e Saúde instalou na área da Cidade dos Meninos o Instituto de Malariologia, que em três anos inaugurou uma fábrica de Hexaclorociclohexano $(\mathrm{HCH})$, também conhecido como Pó de Broca, e ainda outros compostos organoclorados, como o diclorodifeniltricloroetano (DDT). A produção química da fábrica destinava-se ao controle de endemias transmitidas por vetores, como malária, febre amarela e doença de Chagas. Na época, era mais barato produzir no país do que importar. Essa situação se inverteu e em 1956 a fábrica foi desativada e toneladas do pesticida foram abandonadas na área da Cidade dos Meninos. A fábrica de $\mathrm{HCH}$ inaugurada dentro da Cidade dos Meninos utilizava como matéria prima o benzeno, fornecido pela Companhia Siderúrgica Nacional, de Volta Redonda, e o cloro, fornecido pela Companhia Eletroquímica Fluminense, de São Gonçalo, ambas no Estado do Rio de Janeiro. Além do $\mathrm{HCH}$, a fábrica também desenvolvia pesquisas com outros pesticidas, como o arsenito de cobre, também conhecido como Verde Paris e o DDT. A partir de 1956, a fábrica, que passa a se chamar "Fábrica de Produtos Profiláticos", produziu até seu fechamento pasta de DDT; pasta de BHC (isômero alfa, enriquecido com gama-HCH); emulsionáveis - DDT; mosquicidas - DDT + Lindano (gama- $\mathrm{HCH}) ;$ rodenticidas, composto "1080 (monofluoroacetato de sódio) e cianeto de cálcio". Em 1988, após divulgação pela mídia da comercialização clandestina de pesticidas nas feiras livres de Duque de Caxias, foi constatada que a origem do produto era da antiga fábrica na Cidade dos Meninos, e estava espalhado em contato direto com o solo em uma área descampada consi- derada posteriormente como foco principal. O Ministério da Saúde retirou os compostos que estavam sobre o solo, 40 toneladas de $\mathrm{HCH}$ que foram acondicionadas em 16 bombonas plásticas e armazenadas na Refinaria de Duque de Caxias. A área da antiga fábrica, hoje é denominada foco principal de contaminação. A utilização de resíduos como material de capeamento das estradas na Cidade dos Meninos, estocagem, manuseio e utilização dos resíduos, inseticida e como material de reboco nas residências, resultou na contaminação em diversos pontos que foram considerados focos de contaminação. Pelas razões acima, enquanto não forem eliminadas as exposições relatadas e realizadas operações seguras de remediação na Cidade dos Meninos, infere-se a existência de rotas passada, presente e futura de exposição a compostos organoclorados. A contaminação ambiental existente na Cidade dos Meninos, bem como os problemas referentes como o estado em que foram mantidas as instalações da antiga fábrica, a manipulação e o destino dos pesticidas remanescentes no local, representam um caso de difícil resolução quanto à implementação de ações que solucionem o dano causado ao meio ambiente e à população da referida localidade face à conduta de todas as partes envolvidas.

\section{4 | Método}

Com o intuito de contextualizar as questões levantadas, adotou-se, prioritariamente, a estratégia de levantamento de dados e informações disponíveis em diferentes fontes documentais de domínio público, sendo utilizados como instrumento no presente trabalho. A partir disso, foi possível realizar um estudo de caso e com isso fazer uma descrição panorâmica sobre o caso de "Cidade dos Meninos", buscando identificar processos relacionados à emergência do problema da contaminação ambiental e exposição humana em diferentes contextos. A pesquisa foi desenvolvida no Curso Superior de Tecnologia em Gestão Ambiental da Universidade Castelo Branco (UCB) na disciplina Monitoramento e Impacto Ambiental. 


\section{5 | Propostas de solução}

O Ministério da Saúde classificou a área como local de perigo urgente para a saúde pública. Diante disso, foram apontadas três ações, como a retirada de toda a população exposta para outra área, acompanhamento da saúde da população exposta e incompatibilidade da presença da população durante a remediação ambiental. Em 2004, foi encaminhado ao Congresso Nacional, o Projeto de Lei $n^{\circ}$ 3.034/2004, estratégia utilizada pela Advocacia Geral da União (AGU) para que a União pudesse indenizar as famílias expostas na Cidade dos Meninos. A criação do referido projeto de lei foi necessária para justificar juridicamente a obrigatoriedade de indenização aos moradores por parte da União, pelo reconhecimento da responsabilidade pelo abandono da fábrica de pesticida por parte do Ministério da Saúde. Em 12 de junho de 2006, foi firmado um Termo de Compromisso entre o Ministério da Saúde, o Estado do Rio de Janeiro e o município de Duque de Caxias. O Termo de Compromisso enquadra todas as ações envolvendo o monitoramento da saúde da população da Cidade dos Meninos, a interrupção da exposição humana e a remediação ambiental, fazendo parte do conjunto de medidas contempladas no "Plano de Ação Cidade dos Meninos". Os Ministérios (da Saúde; das Cidades; da Agricultura, Pecuária e Abastecimento; da Justiça; do Meio Ambiente e do Planejamento Orçamento e Gestão) para articular, integrar, acompanhar e gerir as ações do "Plano de Ação de Cidade dos Meninos" cria o Grupo de Trabalho Interministerial (GTI) pela Portaria Interministerial no. 1.557, de $1^{\circ}$ de agosto de 2008 e, por meio da Portaria $\mathrm{n}^{\circ} 1182$ de junho de 2009 , constituiu o grupo. Entre as ações deste plano de ações destacam-se: a elaboração de uma proposta de uso futuro da área da Cidade dos Meninos e a atualização cadastral da população. Este Grupo de Trabalho Interministerial (GTI) possui o desafio de resolver o problema da exposição à contaminação ambiental na área.

\section{6 | Resultados e discussões}

A Constituição Federal determina que a todos seja garantido o direito ao meio ambiente ecologicamente equilibrado, de uso comum do povo e fundamental para a existência de uma saudável qualidade de vida (BRASIL, 2005). Caberá ao poder público e à coletividade, segundo dispõe o art. 225 da CF, a defesa e a preservação ambiental para os presentes e futuras gerações. Com o objetivo de regulamentar o referido artigo, entrou em vigor, nos seus aspectos penais, a Lei no 9.605/98, conhecida como a Lei de Crimes Ambientais. O Projeto de Lei $n^{\circ} 3.034 / 04$ foi proposto pelo executivo para autorizar a União a conceder indenização por danos morais e materiais aos ocupantes de imóveis residenciais a ela pertencentes, na localidade denominada "Cidade dos Meninos", que tenham sido expostos a compostos organoclorados. A indenização proposta era de $R \$ 50.000$ (cinquenta mil) reais por família, e $\mathrm{R} \$ 10.000$ (dez mil) reais a mais por pessoa nas famílias que têm mais de cinco pessoas. Teriam direito à indenização somente as famílias cadastradas. Abre-se questionamento em relação à supressão do Art. $2^{\circ}$, segundo o qual o recebimento da referida indenização ficaria condicionada à desocupação dos imóveis e à assinatura de termo de transação no qual os ocupantes renunciem a qualquer direito ou ação relativa à exposição ao referido risco ambiental, sendo de fundamental relevância para uma possível solução. A discussão gira em torno do projeto de lei perder a sua função primordial de interromper a exposição da população na área da Cidade dos Meninos. O fato é que permanece o impasse. A efetividade relacionada à reparação do dano ambiental é uma das questões mais polêmicas tratadas atualmente, tanto pela doutrina quanto pelos tribunais, pois afeta o indivíduo, considerado singularmente ou em sua coletividade, na busca de um meio ambiente ecologicamente equilibrado, assegurado constitucionalmente no art. 225 da CF/88. Enquanto alguns moradores considerarem plausiveis as opções de desocupação de seus imóveis, outros mais antigos resistem e não aceitam a possibilidade da referida desocupação. Portanto, observa-se o conflito de interesses dentro da própria população, que dificulta, inclusive, a negociação para atingir metas vantajosas para a comunidade como um todo. Houve propostas para evacuação da área e indenização da população, porém a população afetada demonstra grande interesse em deixar as áreas contaminadas se receberem suas indenizações. De todas as providências 
adotadas para interromper a exposição humana aos organoclorados, e que tem gerado grande dificuldade, é a retirada dos moradores, objeto principal de todas as ações implementadas nos âmbitos judicial e administrativo. É importante frisar que os moradores da localidade são em sua maioria de baixa renda, não possuindo condições financeiras para adquirir novas habitações; esta situação poderá ser minimizada por intermédio de indenização condicionada ao PL 3.034/2004. Há que se considerar que os habitantes desta localidade usufruem dos imóveis de forma gratuita, uma vez que esta é patrimônio da União conforme EM n. ${ }^{\circ}$ og6/GM 2003.

\section{7 | Conclusão}

Partindo do princípio de que a saúde do homem depende diretamente da boa saúde do ambiente, somente investindo em programas de Educação Ambiental para o povo é possível a formação de uma consciência ecológica voltada para melhores condições de vida. A educação ambiental representa um instrumento capaz de provocar na sociedade as mudanças de comportamento requeridas pela realidade ambiental atual. Somente a partir da formação de uma consciência crítica desta realidade se mudarão valores, hábitos e atitudes, optando por comportamentos menos agressivos com relação ao ambiente e inter-relações humanas. Neste caso, só a Educação Ambiental pode provocar mudanças no comportamento e na relação homem, sociedade e natureza. A formulação e a implementação de políticas ambientais dependem diretamente de uma cadeia de agentes sociais, cujos elos vão desde o Estado, agentes públicos, cientistas, setores econômicos, meios de comunicação, sociedade civil organizada e a população em geral. Todos os segmentos sociais devem ter como objetivo que as políticas ambientais sejam formuladas e executadas de forma a refletir o máximo possível as suas pretensões. Com isso, os gastos do dinheiro público serão mais eficientes, existirá satisfação por parte da população com o desempenho dos agentes governamentais, ocorrerá uma efetiva proteção ambiental, bem como o desenvolvimento social e econômico sustentável. Infelizmente, esses programas nem sempre estão de acordo com os anseios e os interesses da população a que se destinam, criando contradições entre os objetivos do formulador, o efeito real e o efeito percebido, gerando conflitos que prejudicam tanto a eficácia quanto o alcance e causam o desperdício de tempo, recursos humanos e financeiros. Enquanto perdurar a inércia para resolução do dano ambiental na Cidade dos Meninos, maiores serão os impactos negativos e externalidades gerados sobre a saúde e o ambiente, consequentemente, o ônus pertencerá a todos os envolvidos.

\section{Referências bibliográficas}

ALMEIDA, J. R.; OLIVEIRA, S. G.; PANNO, M. Perícia ambiental. Rio de Janeiro: Thex. 2003.

BRASIL, Avaliação de risco à saúde humana por resíduos de pesticidas organoclorados em cidade dos meninos, RJ. 2004

MEDINA, N. M.; SANTOS, E. Educação ambiental: uma metodologia participativa de formação. Petrópolis: Vozes. 2005.

SILVA, J. A. Direito ambiental constitucional. São Paulo: Malheiros Editores. 2002. 